\title{
Criatividade como habilidade interdisciplinar ${ }^{1}$ Creativity as an interdisciplinary skill
}

\author{
Ersin Karademir ${ }^{*}$
}

\begin{abstract}
RESUMO
Existem muitos estudos teóricos e experimentais sobre o conceito de habilidade. Na educação, a criatividade é considerada uma das habilidades mais importantes com sua natureza dinâmica e complexa. É uma habilidade de alto nível que ocorre interdisciplinarmente, na qual os indivíduos produzem produtos novos e úteis como resultado da interação entre habilidade, processo e ambiente. Com base nessa noção, o primeiro objetivo deste estudo é fornecer uma revisão do desenvolvimento de estudos teóricos e experimentais, que descrevam diferentes classificações e definições de habilidades e sua natureza dinâmica. O segundo objetivo do estudo é apresentar uma prática em sala de aula para ampliar a criatividade de alunos talentosos por meio de observações de professores (pesquisadores) e produtos do projeto. $\mathrm{O}$ autor realizou uma revisão da literatura recente (HU; ADEY, 2002; KARADEMIR, 2016, 2017) sobre a criatividade dos alunos do ensino fundamental / médio. O resultado do estudo prático em sala de aula revelou que a habilidade criativa pode ser desenvolvida por meio de atividades de design e projeto.
\end{abstract}

Palavras-chave: Habilidade. Criatividade. Alunos talentosos. Interdisciplinaridade.

\begin{abstract}
There are many theoretical and experimental studies on the concept of skill. In education, creativity is regarded as one of the most important skills with its complex dynamic nature. It is a high level skill that occurs interdisciplinarily whereby individuals produce new and useful product as a result of the interaction between skill, process and environment. Based on this notion, the first aim of this study is to provide a review of the development of theoretical
\end{abstract}

1 Traduzido por David Harrad. E-mail: davidharrad@hotmail.com

* Eskisehir Osmangazi University. Faculty of Education. Eskisehir, Turkiye. E-mail: ekarademir@ogu.edu.tr - https://orcid.org/0000-0002-8519-622X 
and experimental studies, which describes different classifications and definitions of skills and its dynamic nature. The second aim of the study is to present a in-class practice to extent creativity of gifted students through teacher (researcher) observations and project products. The author performed a review of the recent literature (HU; ADEY, 2002; KARADEMIR, 2016, 2017) on primary-middle school / gifted students 'creativity. The result of the in-class practice study revealed that creativity skill can be developed by design and project based activities.

Keywords: Skill. Creativity. Gifted Students. Interdisciplinarity.

\section{O conceito de habilidades}

Os traços de caráter dos estudantes determinam a forma como interagem com seu ambiente e seu comportamento, assim como sua capacidade de aplicar conhecimentos, resolver problemas para completar tarefas. A aquisição de habilidades pelos estudantes é cognitiva (pensamento lógico, intuitivo e criativo) e/ou prática (destreza e capacidade de utilizar métodos, materiais, ferramentas). Uma abordagem holística deve ser seguida quando da elaboração em profundidade do currículo, levando em conta quatro dimensões de educação: conhecimento, habilidade, caráter e metacognição. É importante alcançar um equilíbrio entre as disciplinas atuais e tradicionais à luz das relações interdisciplinares. Quando a informação é utilizada, ela se torna uma habilidade, e quando combinada com a informação, ela se encontra apenas no loop de feedback. Além disso, o metacognição contribui para o processo da pessoa se expressar como ela é e aprender a aprender sobre si mesmo, bem como contribui para a criação das outras três dimensões (DE CORTE, 2003; BIALIK; FADEL, 2015).

As habilidades são classificadas como disciplinares/interdisciplinares ou de nível básico/superior. Elas são construídas com base nas habilidades existentes já adquiridas pelos indivíduos ou também podem ser descobertas, desenvolvidas ou atrapalhadas durante a educação. A prestação de um serviço educacional de qualidade pode determinar o desenvolvimento bem-sucedido ou a perda das capacidades e habilidades de um indivíduo. Os indivíduos diferem em suas habilidades, estilos e estratégias de aprendizagem. É importante focar na identificação dos pontos fortes e fracos de cada indivíduo antes de tentar melhorar suas habilidades. É igualmente importante lidar com múltiplas disciplinas enquanto se trata de múltiplas habilidades durante a configuração do currículo, levando em conta o conceito de habilidades interdisciplinares e 
prestando atenção às habilidades holísticas que o indivíduo necessita, ao invés de habilidades singulares (KARADEMIR, 2017).

\section{Características de habilidades}

Habilidade é um conceito com várias características. Algumas dessas características são as seguintes (OECD, 2005; GUNES, 2012; KARADEMIR, 2017):

Habilidade possui um conteúdo complexo e inclui conhecimentos, práticas, atitudes, métodos, etc. entrelaçados que precisam se integrar durante a implementação. A estrutura complexa da habilidade requer um planejamento cuidadoso ao preparar e ensinar. A qualidade da educação tem um impacto direto sobre o desenvolvimento das habilidades.

A aquisição de habilidades é um processo em constante evolução e não é restrita além da educação formal. Ela é desenvolvida ao longo da vida e varia de acordo com a idade e o nível de educação. As atividades voltadas para o desenvolvimento de habilidades precisam ser baseadas no conhecimento prévio do estudante, bem como na realização de novos aprendizados com várias formas de interação em mente para identificar e fomentar as habilidades do indivíduo.

Habilidade é uma estrutura que deriva de vidas passadas dos indivíduos e emerge no futuro. Ela também surge da necessidade de criar situações possíveis para eventos futuros e pode indicar comportamentos futuros: por esta razão, o estudante/indivíduo deve ser incentivado a se tornar autônomo e aprender a aprender por conta própria.

Habilidade deve ser abordada holisticamente. O principal fator no treinamento de habilidades é lidar com um evento/emprego/situação em sua totalidade. Uma situação em que a habilidade está pela metade ou falta não pode ser considerada. Isto ocorre tanto na própria vida quanto no exercício de uma profissão (BISSONNETTE; RICHARD, 2001).

\section{Habilidades na educação: habilidades do século XXI}

Como mostra a Tabela 1, é possível dividir as habilidades em duas partes no contexto geral. 
TABELA 1 - HABILIDADES NA EDUCAÇÃO

\begin{tabular}{ll}
\hline Conhecimentos básicos/Habilidades disciplinares & Habilidades aplicadas / avançadas \\
\hline Língua nativa & Pensamento crítico \\
Leitura & Solução de problemas \\
Escrita & Comunicação (Verbal / Escrita) \\
Matemática & Trabalho em equipe / Colaboração \\
Ciência & Diversidade \\
Economia & Informação / Tecnologia \\
Letras e humanidades & Liderança \\
Línguas estrangeiras & Criatividade \\
História / Geografia & Inovação \\
Medição & Aprendizagem ao longo da vida \\
Observação & Ética \\
& Autoaprendizagem \\
\hline
\end{tabular}

FONTE: Karademir (2020, p. 87-126, our translation).

As habilidades podem ser divididas em duas partes. Veja a Tabela 1. As habilidades, os conhecimentos e a expertise que os estudantes devem dominar para ter sucesso no trabalho e na vida, são uma mistura de conhecimento de conteúdo, habilidades específicas, expertise e letramentos. A implementação de cada habilidade do século XXI requer o desenvolvimento do conhecimento e a compreensão das disciplinas acadêmicas essenciais entre todos os estudantes. Aqueles que podem pensar criticamente e se comunicar de forma eficaz devem construir a partir de uma base de conhecimento das disciplinas acadêmicas essenciais. 


\section{As 4 Habilidades C do século XXI: Colaboração, comunicação, pensamento crítico e criatividade}
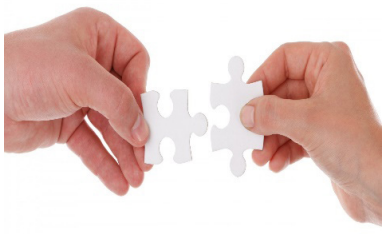

Colaboração
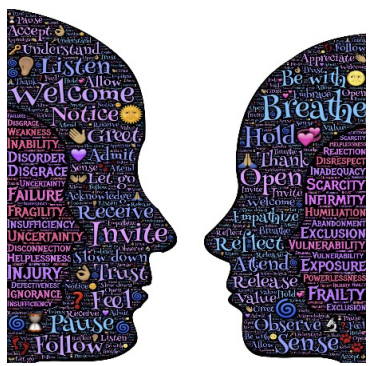

Pensamento Crítico

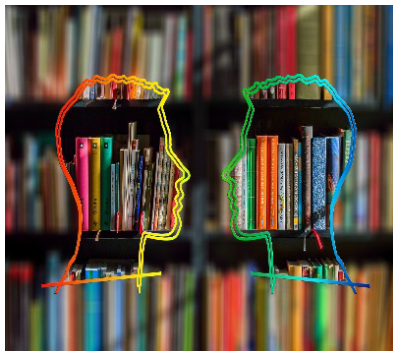

Comunicação

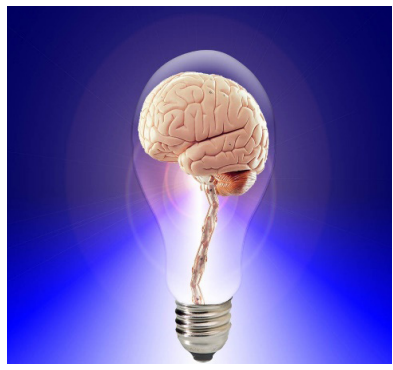

Criatividade

FONTE: Fotos tiradas do site Pixabay.com livre de royalties.

As habilidades de criatividade, pensamento crítico, colaboração e comunicação devem ser consideradas de forma holística e inter-relacionada, não individual e separadamente, dentro dos sistemas educacionais. Para desenvolvê-las plenamente, um método interdisciplinar deve ser utilizado. Há muitos métodos e técnicas interdisciplinares. As quatro habilidades $\mathrm{C}$ do século XXI fornecem aos estudantes uma perspectiva ampla. O sucesso dos estudantes tanto em suas aulas quanto em suas vidas depende do desenvolvimento destas habilidades. É importante que os estudantes utilizem estas habilidades juntas como um todo para ganhar experiência na vida cotidiana. O pensamento crítico ensina os estudantes a questionar afirmações e a buscar a verdade. A criatividade ensina os estudantes a pensar de uma forma que lhes seja única. A colaboração proporciona aos estudantes a oportunidade de trabalharem juntos e realizarem tarefas maiores. A comunicação ensina os estudantes a transmitir ideias. 
Abordagens fundamentadas também fazem parte desses métodos e técnicas, criando um modelo entrelaçado com problemas do mundo real na educação sobre habilidades. É inevitável utilizar habilidades de criatividade, pensamento crítico, colaboração e comunicação nas soluções destes problemas reais nos sistemas educacionais. Nestes casos, tanto professores quanto estudantes desempenham um papel importante no desenvolvimento e domínio destas habilidades.

\section{TABELA 2 - HABILIDADES DO SÉCULO XXI E SUAS DEFINIÇÕES}

\begin{tabular}{|c|c|c|}
\hline Habilidades & Sub-habilidades & Definições \\
\hline \multirow{3}{*}{$\begin{array}{l}\text { Habilidades de } \\
\text { aprendizagem e } \\
\text { inovação }\end{array}$} & $\begin{array}{l}\text { Pensamento crítico e solução } \\
\text { de problemas }\end{array}$ & $\begin{array}{l}\text { Raciocínio racional e escolhas difíceis; } \\
\text { compreensão das relações entre sistemas } \\
\text { Capacidade de identificar, examinar e } \\
\text { resolver problemas }\end{array}$ \\
\hline & Criatividade e inovação & $\begin{array}{l}\text { Desenvolvimento, } \\
\text { e compartilhamento de novas ideias } \\
\text { com outros; disposição a estar aberto a } \\
\text { perspectivas novas e diferentes. Elaboração, } \\
\text { aprimoramento, análise e avaliação das } \\
\text { próprias ideias a fim de melhorar e maximizar } \\
\text { os esforços criativos }\end{array}$ \\
\hline & Comunicação e colaboração & $\begin{array}{l}\text { Compreensão, utilização e preparação } \\
\text { de ferramentas eficazes de comunicação } \\
\text { verbal, escrita e multimídia em diferentes } \\
\text { formas e ambientes. Trabalho em equipe e } \\
\text { liderança; adaptação a diferentes papéis e } \\
\text { responsabilidades; trabalho eficiente com } \\
\text { os outros; colocar-se no lugar dos outros; } \\
\text { respeitar as diferenças }\end{array}$ \\
\hline \multirow{3}{*}{$\begin{array}{l}\text { Habilidades de } \\
\text { informação, } \\
\text { mídia e } \\
\text { tecnologia }\end{array}$} & Letramento em informação & \multirow{3}{*}{$\begin{array}{l}\text { Analisar, acessar, utilizar, adaptar, avaliar } \\
\text { e criar informações em diferentes formas e } \\
\text { ambientes }\end{array}$} \\
\hline & Letramento midiático & \\
\hline & $\begin{array}{l}\text { Letramento em TICs } \\
\text { (Tecnologia, Informação e } \\
\text { Comunicação) }\end{array}$ & \\
\hline
\end{tabular}

(Continua) 


\begin{tabular}{lll}
\hline & $\begin{array}{l}\text { Flexibilidade e } \\
\text { adaptabilidade }\end{array}$ & $\begin{array}{l}\text { Cumprir a responsabilidade individual e ter } \\
\text { flexibilidade na vida pessoal, nos negócios } \\
\text { e em público; estabelecer e alcançar altos } \\
\text { padrões e metas para si mesmo e para os } \\
\text { outros }\end{array}$ \\
\cline { 2 - 3 } $\begin{array}{c}\text { Habilidades de } \\
\text { vida e de carreira }\end{array}$ & $\begin{array}{l}\text { Iniciativa e } \\
\text { autodirecionamento } \\
\text { próprias necessidades de aprendizagem; } \\
\text { identificar recursos apropriados; transferir o } \\
\text { aprendizado de um campo para outro }\end{array}$ \\
\cline { 2 - 3 } & $\begin{array}{l}\text { Habilidades sociais e } \\
\text { transculturais }\end{array}$ & $\begin{array}{l}\text { Agir com responsabilidade, tendo em } \\
\text { mente os interesses e os direitos dos outros; } \\
\text { demonstrar comportamento ético na vida } \\
\text { pessoal, nos negócios e em público }\end{array}$ \\
\cline { 2 - 3 } & $\begin{array}{l}\text { Productividade e } \\
\text { responsabilização } \\
\text { (accountability) }\end{array}$ & \begin{tabular}{l} 
Liderança e responsibilidade \\
\cline { 2 - 3 }
\end{tabular}
\end{tabular}

FONTE: Partnership for 21st Century Skills (2003, our translation).

Conforme visto na Tabela 2:

As pessoas no século XXI convivem com tecnologias e ambientes mediáticos, marcados por várias características. Elas têm acesso a uma abundância de informações, mudanças rápidas nas ferramentas tecnológicas e a capacidade de colaborar e fazer contribuições individuais em uma escala sem precedentes. Cada vez mais, os governos e as empresas exigem dos cidadãos e dos trabalhadores do século XXI uma série de habilidades funcionais e de pensamento crítico relacionadas à informação, à mídia e à tecnologia.

As habilidades de aprendizagem e inovação são cada vez mais reconhecidas como aquelas que separam os estudantes que estão preparados para situações e ambientes de trabalho cada vez mais complexos no século 21, e aqueles que não estão. Habilidades de criatividade, pensamento crítico, comunicação e colaboração como essenciais na preparação dos estudantes para o futuro (PARTNERSHIP FOR 21ST CENTURY SKILLS, 2013). 
FIGURA 1 - RESULTADOS PARA ESTUDANTES DO SÉCULO XXI

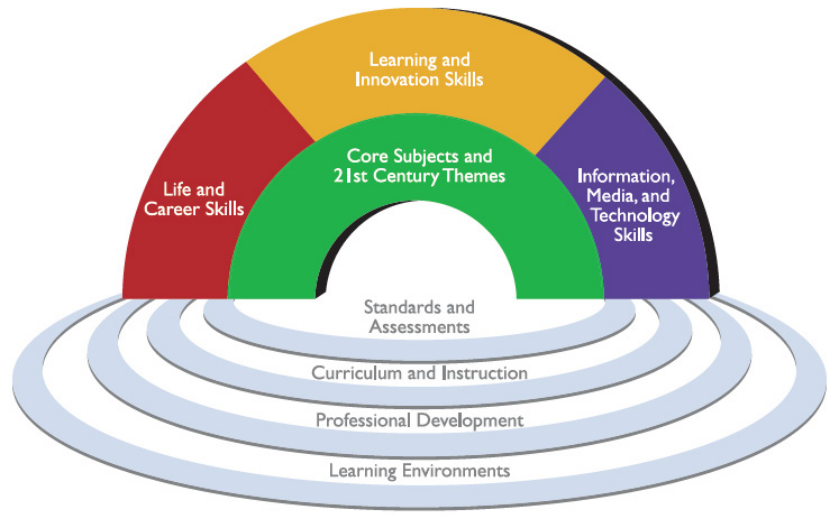

FONTE: Partnership for 21st Century Skills (2013).

A Figura 1 representa cada elemento de forma distinta para fins descritivos. Os componentes estão totalmente interligados no processo de ensino e aprendizagem do século XXI. Os elementos descrevem os sistemas críticos necessários para garantir a preparação de cada estudante do século XXI. Os padrões, avaliações, currículo, instrução, desenvolvimento profissional permanente e ambientes de aprendizagem do século XXI devem ser alinhados para produzir resultados do século XXI para os estudantes de hoje.

\section{Criatividade enquanto habilidade}

A definição de criatividade mudou com o passar dos anos. Os pesquisadores descrevem o fenômeno da criatividade, sendo que a descrição varia de acordo com muitas ideias e abordagens diferentes, incluindo diferentes expressões, tais como um reflexo da inteligência, um processo inconsciente, capacidade de resolver de problemas e um ato de pensar baseado em uma conotação (MACKINNON, 1962; GUILFORD, 1968; KOBERG; BAGNALL, 2003; MALAGA, 2000; ADAMS, 2001). A criatividade também é vista como uma forma individual de pensar e examinar quantitativamente a personalidade criativa, a capacidade do indivíduo de compreender, através de abordagens psicométricas (TORRANCE, 1972,). Weis (1993) definiu a criatividade como a utilização da mente para criar novas ideias, dar à mente uma nova forma, utilizar a mente para criar algo novo, fazer 
algo novo, produzir novas ideias usando a imaginação, projetar algo novo. Criar algo novo é inventar. Alguns pesquisadores examinam a criatividade com base em fatores organizacionais ou sociais e examinam como esses fatores afetam a criatividade (ARGYRIS; SCHÖN, 1996). Em 2004 uma nova definição foi proposta por Plucker, Beghetto e Dow, definindo a criatividade como a interação entre aptidão, processo e ambiente pelo qual um indivíduo ou grupo produz um produto perceptível que é ao mesmo tempo novo e útil como definido dentro de um contexto social. Uma definição de criatividade geralmente de consenso foi proposta por Chung, 2012; Hennessey; Amabile, 2010, definindo criatividade que envolve o desenvolvimento de um novo produto, ideia ou solução de problemas que seja de valor para o indivíduo e/ou para o grupo social maior. Outros baseiam suas pesquisas em testes e medições, utilizados para medir e melhorar seu desempenho em termos da criatividade individual e do processo de informação na mente (TORRANCE, 1972; WEISER, 1993; KARADEMIR, 2016; ONUR; ZORLU, 2017).

A pessoa criativa descobre gradualmente lugares desconhecidos através das formas que todos conhecem. Em outras palavras, cria eventos ou produtos diferentes / desconhecidos / inexplorados, utilizando formas / métodos / técnicas comuns. O processo criativo começa com o perguntar-se e o sonho. Não se pode produzir soluções para um problema sem sonhar. Por esta razão, é necessário planejar atividades educacionais de forma a aumentar as habilidades dos estudantes para transformar suas habilidades criativas em uma habilidade superior. Ao fazer isso, é importante não permitir que as atividades educacionais impeçam e reduzam a criatividade.

Arenofsky (2000) identificou fatores que impedem a criatividade e seu desenvolvimento, conforme segue:

- Críticas: A crítica contínua a ideias ou produtos produzidos tanto individualmente quanto em grupo por outros afeta negativamente a criatividade, porque esta situação impede constantemente o desenvolvimento da ideia ou do produto.

- Estresse: As pressões aplicadas sobre os indivíduos fazem com que estes aumentem seus níveis de estresse e percam suas características criativas.

- Dúvida: Dúvidas sobre as ideias ou produtos produzidos causam a perda da originalidade dessa ideia ou produto.

- Rotina: A criatividade perde seu valor com o tempo, pois cada ideia ou produto produzido é feito da mesma maneira e não são oferecidas alternativas diferentes.

- Problemas no ajuste do tempo: O desejo de manter um pensamento criativo entre determinados períodos de tempo afetará negativamente a criatividade. 
- Meio ambiente: Sentir-se desconfortável no ambiente em que o indivíduo está localizado e as condições ambientais em que ele/ela está localizado podem afetar a criatividade negativamente.

Ao tratar de fatores que afetam negativamente a criatividade, é necessário considerar as características da pessoa criativa.

FIGURA 2 - RELAÇÃO ENTRE A CRIATIVIDADE E A PESSOA CRIATIVA

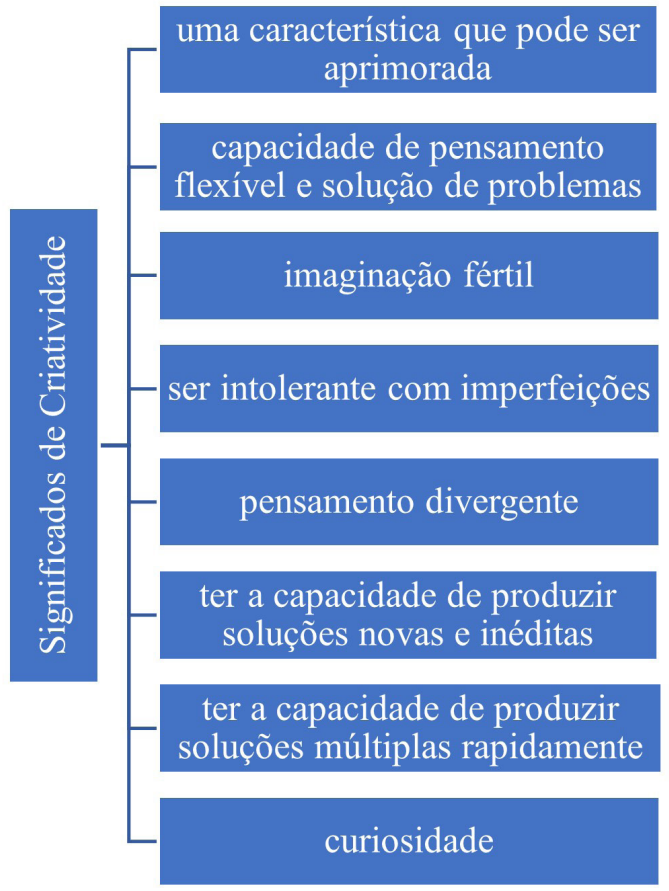

FONTE: Onur e Zorlu (2017, our translation).

Segundo a Figura 2, as características da pessoa criativa têm algo que pode ser melhorado. Uma pessoa criativa é alguém que tem a capacidade de síntese por ser curiosa e paciente e fazer descobertas por ser aventureira com experimentos e pesquisas (USTUNDAG, 2002).

Wechsler (1991), Piske (2014), Bahia e Trindade (2013) indicam maneiras de trabalhar com potencial criativo, focando na liberdade de expressão durante o ensino e no respeito mútuo, o que pode gerar possibilidades para reconhecer as diferentes oportunidades durante o processo de ensino e aprendizagem. Estas incluem: 
- Proporcionar aos estudantes a liberdade de escolher entre diferentes maneiras de resolver um problema, diversificando as possibilidades de realizar uma atividade proposta.

- Ajudar os estudantes a expressar ideas diferentes das suas; proporcionar oportunidades de exploração de ambientes, saindo sempre que possível do espaço físico limitado da sala de aula.

- Incentivar os estudantes a fazer seus projetos pessoais como um meio de reconhecer suas habilidades e talentos; incentivá-los a serem questionadores.

- Permitir que os estudantes façam perguntas e testem suas hipóteses, mesmo que a princípio pareçam inadequadas ou absurdas.

- Incentivar a curiosidade pela aprendizagem e desincentivar o foco na memorização.

- Dar opções aos estudantes para fazer pesquisas sobre diferentes áreas do conhecimento, entre outras possibilidades de trabalhar com criatividade (PISKE et al., 2016)

Os professores trabalham com muitos tipos de estudantes no processo da revelação de suas habilidades criativas na sala de aula. Enquanto alguns desses estudantes estão no nível regular, alguns deles são estudantes com altas habilidades.

FIGURA 3 - O CONJUNTO DE TALENTOS RESULTANDO DA INTERAÇÃO DOS COMPONENTES QUE LEVAM UMA PESSOA A SER SUPERDOTADA

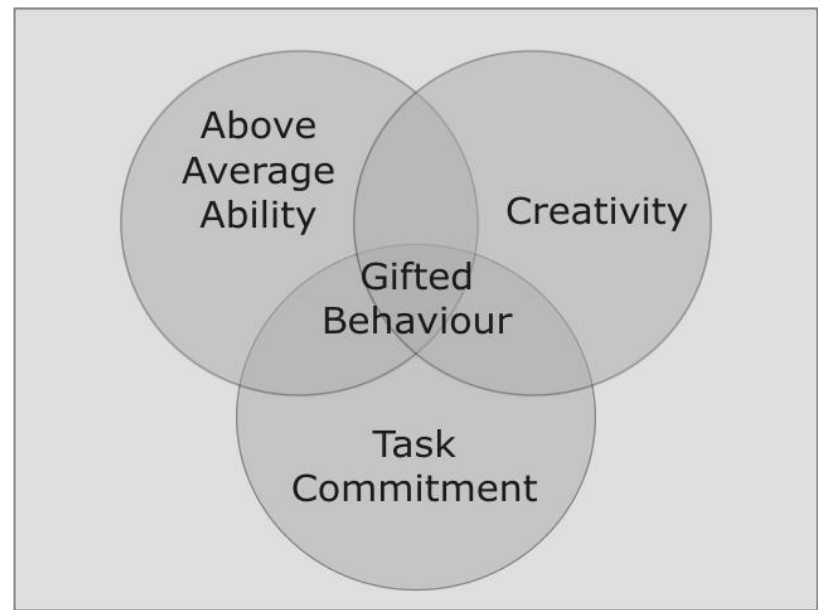

FONTE: Renzulli (1999). 
Segundo o modelo na Figura 3, indivíduos com estes três anéis são considerados superdotados e espera-se que tenham um treinamennto especial (AKKANAT, 2012). Como se vê no modelo, a criatividade é um componente importante das características de comportamentos de superdotação. A criatividade é uma habilidade mental e sociocultural relacionada ao ambiente encontrada em todos os indivíduos em qualquer idade, e não uma habilidade sobrenatural, um poder místico dado aleatoriamente por Deus, sob o monopólio de um número limitado de pessoas superdotadas na sociedade.

A criatividade é composta de pelo menos quatro componentes básicos. Estes são: processo criativo, produto criativo, indivíduo criativo e caso criativo. A criatividade é frequentemente um aspecto importante do talento científico. Resolver problemas, gerar hipóteses, projetar experimentos e inovações técnicas requer uma forma especial da criatividade única da ciência. Para que estudantes talentosos sejam ajudados a encontrar sua interseção criativa, mudanças significativas e fundamentais devem ser feitas na maneira como os educadores pensam sobre o ensino e o aprendizado (HENNESSEY, 2004; KARADEMIR, 2016).

É vital que o corpo docente esteja preparado para criar um ambiente estimulante de criatividade que desperte o interesse de estudantes talentosos e aumente a motivação para aprender. Para isso, os professores precisam conhecer os interesses e as especificidades de seus estudantes, por exemplo, se o estudante gosta de desenhar, é importante que as atividades se concentrem no desenho, se o estudante gosta de fazer pesquisas, as atividades que envolvem pesquisas são essenciais para que este estudante aprenda. Em geral, trabalhar com arte pode ser uma boa opção para desenvolver a criatividade (PISKE et al., 2016).

\section{Criatividade em estudantes com superdotação}

A criatividade científica compreende o produto, o traço e o processo. $\mathrm{O}$ "produto" depende do produto técnico, do conhecimento científico, do fenômeno científico e do problema científico e o traço é avaliado por três estruturas denominadas fluência, flexibilidade e originalidade. Na criatividade científica, o processo depende da imaginação e do pensamento (HU; ADEY, 2002).

O estudante com superdotação, que aprende mais rápido que seus pares, é um indivíduo que é o líder em criatividade, arte e capacidade de liderança, tem habilidades acadêmicas especiais, pode entender ideias abstratas, gosta de agir independentemente em seus interesses e tem um alto nível de desempenho 
(MNE, 2016). Além disso, ele expressa a capacidade de criar algo especial e uma combinação de todas estas características, diferente de seus pares em termos de talento, criatividade, motivação e superioridade mental (KOCAK; ICMENOGLU, 2012). Por esta razão, espera-se que estudantes talentosos adquiram pensamento criativo, descoberta, invenção, sucesso nas relações sociais, inovação, liderança, comunicação e habilidades artísticas (MNE, 2016).

Crianças com superdotação são aqueles indivíduos que têm um alto nível de desempenho em áreas relacionadas à capacidade mental, criativa ou de liderança, ou em campos acadêmicos específicos e que precisam de treinamento especial para desenvolver suas habilidades (DAVASLIGIL, 2004). Além disso, a sobredotação inclui "talento de alto nível", "criatividade" e "motivação" (RENZULLI, 1999).

Embora a definição de talento tenha sido ampliada e reduzida ao longo do tempo, devemos levar em conta os diferentes tipos de habilidades na educação de pessoas com superdotação quando usamos os conceitos de "diferença" e "criatividade" em cada definição. Uma habilidade pode ser adquirida, desenvolvida ou extinta, a menos que o treinamento seja realizado. Quanto mais habilidades forem identificadas, mais fácil será para estudantes e professores alcançarem os objetivos básicos da educação. $\mathrm{O}$ conceito de criatividade é muitas vezes confundido com o conceito de inteligência. As pessoas criativas são aquelas que têm habilidades de pensamento multifacetadas e não aquelas com alta inteligência. Entretanto, estes dois conceitos são diferentes um do outro. A inteligência é essencial para a criatividade, mas não é suficiente (LIN et al., 2003). Mesmo que as pessoas criativas sejam geralmente inteligentes, os indivíduos inteligentes podem nem sempre ser criativos em tudo.

Os estudantes com superdotação exigem métodos e técnicas de ensino diferentes dos de seus colegas. Como estes estudantes aprendem mais rapidamente e de maneiras diferentes, o currículo precisa ser diferenciado para atender às necessidades dos superdotados. A diferenciação curricular é criada para fomentar o desenvolvimento das habilidades criativas dos estudantes com sobredotação no desenho, enriquecimento, extensão, aceleração do currículo (TORTOP, 2015).

\section{Diferenciação do Currículo}

Diferenciação curricular significa proporcionar diferentes atividades de aprendizagem para crianças da mesma idade com diferentes necessidades e preferências de aprendizagem (KULIK, J.; KULIK, C., 1997). Ao lidar com estudantes com superdotação, é especialmente importante considerar as 
diferenças que podem ser alcançadas acima do que outros estudantes da classe trabalham.

\section{Enriquecimento}

Enriquecimento se refere à flexibilidade horizontal, e expansão refere-se à flexibilidade vertical. Enriquecimento é qualquer aprendizagem ou atividade que esteja fora da educação regular para a maioria dos estudantes. É realizado além do currículo criado e não substitui o programa regular, é complementar. O enriquecimento pode ampliar os horizontes dos estudantes, ajudá-los a olhar para diferentes aspectos de seu trabalho e desenvolver a criatividade. Enriquecimento significa trabalhar de uma maneira diferente do habitual, envolvendo grupos de estudantes que trabalham juntos.

\section{Extensão}

A extensão permite que o estudante se movimente mais rápido do que o currículo regular. Isto significa pular propositalmente os capítulos/temas antes de prosseguir. Em outras palavras, pode ser necessário comprimir o currículo para torná-lo mais intenso e complexo. Estudos neste contexto permitem que o estudante trabalhe individualmente.

A extensão e o enriquecimento podem ocorrer em uma sala de aula onde são ensinadas mais atividades, ou atividades mais desafiadoras, para lidar com estudantes com superdotação, ou, alternativamente, além do ambiente regular da sala de aula. Quando atividades de extensão e enriquecimento são realizadas em sala de aula, estas devem ser suficientemente diferentes do programa seguido por outros estudantes na sala de aula.

\section{Aceleração}

Acelerar as crianças para os anos escolares acima da idade cronológica é uma questão importante tanto para os educadores quanto para os pais. Atualmente, os principais acadêmicos em educação para pessoas com superdotação nos Estados Unidos e na Austrália apoiam o uso da aceleração em condições favoráveis, quando as necessidades da criança podem ser adequadamente atendidas. 


\section{Prática na sala de aula: determinando habilidades de criatividade em estudantes com superdotação}

O objetivo principal deste estudo é identificar a extensão da criatividade dos estudantes com superdotação através da prática em sala de aula. Para este fim, foi solicitado aos estudantes que projetassem produtos que facilitassem suas vidas. De acordo com este propósito, foi solicitado aos estudantes que projetassem projetos e sua adequação à extensão da criatividade foi determinada. Procurou-se explicar a adequação dos projetos dos estudantes de acordo com subescalas de fluência, originalidade e flexibilidade, conforme a definição de Hu e Adey (2002), através de observações do professor (pesquisador) e dos produtos dos projetos.

Nesta prática em sala de aula, observou-se que as habilidades de criatividade mudaram no contexto de diferentes dimensões dentro do escopo dos estudos dos projetos realizados por estudantes com superdotação no ensino fundamental. A mudança e o desenvolvimento da criatividade dos estudantes com superdotação no contexto das dimensões de criatividade especificadas por Hu e Adey (2002) foram observados. Em estudos de longo prazo neste contexto, a formação de habilidades pode exigir um certo processo. Ao passo que este processo pode precisar de algumas lições em algumas habilidades, outras podem levar muito tempo. Portanto, as habilidades devem ser acompanhadas e avaliadas no processo. Um estudo é realizado em uma perspectiva ampla sobre a formação de habilidades (KARADEMIR, 2016). Este artigo abrange a parte sobre habilidades de criatividade.

\section{A teoria da prática na sala de aula}

Como visto na Figura 4, de acordo com Hu e Adey (2002) a criatividade científica tem três partes denominadas produto, traço e processo. "Produto" depende do produto técnico, do conhecimento científico, do fenômeno científico e do problema científico. O traço é avaliado por três estruturas denominadas fluência, flexibilidade e originalidade. Na criatividade científica, o processo depende da imaginação e do pensamento. 
FIGURA 4 - O MODELO DE CRIATIVIDADE DA ESTRUTURA CIENTÍFICA

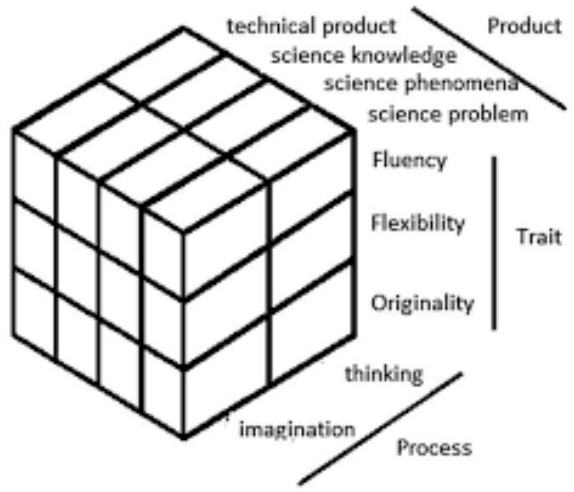

FONTE: Hu e Adey (2002) e Karademir (2016).

Fluência: É ser capaz de gerar muitas ideias que podem ser a resposta para um problema. Por exemplo, encontrar diferentes usos de um tijolo ou encontrar títulos adequados para um conto. Pessoas criativas podem apresentar uma série de ideias como solução para o problema (HU; ADEY, 2002). Por exemplo; um estudante que produz 10 soluções diferentes para uma situação problemática em 5 minutos tem mais fluência e maior habilidade criativa do que um estudante que produz 5 soluções no mesmo período de tempo (RAHMAN, 1999).

Flexibilidade: É ser capaz de trazer diferentes perspectivas sobre uma questão, revelar diferentes dimensões, gerar ideias em diferentes categorias, abordar uma situação a partir de diferentes perspectivas. Quanto mais as ideias geradas tratam o problema a partir de ângulos diferentes, maior a flexibilidade. Pessoas criativas oferecem soluções para problemas a partir de diferentes perspectivas (HU; ADEY, 2002). A flexibilidade de um estudante para passar de uma abordagem para outra está relacionada à condição de usar diferentes estratégias intelectuais. Uma criança com um nível muito baixo de flexibilidade mostra um padrão rígido de pensamento. Entretanto, uma criança que tem flexibilidade excessiva é capaz de passar de uma abordagem para outra (SUNGUR, 1997).

Originalidade: É o caso de ser único em pensamento e ação. Considera-se que quanto menos pessoas pensam na ideia gerada, mais original ela é. As pessoas criativas geram ideias originais (HU; ADEY, 2002). 


\section{Determinando as habilidades / sub-habilidades esperadas / visadas}

Na parte relativa à determinação de habilidades, foi realizada a prática relacionada às habilidades que contêm diferentes disciplinas. Foi demonstrada a adequação dos estudantes com múltiplos talentos a partir do feedback obtido dos estudantes com superdotação após o estudo. Na Tabela 3 , habilidades de vida esperadas / visadas, é possível ver como as habilidades-alvo são reveladas após a atividade antes do evento. Esta tabela pode diferir dependendo das habilidades direcionadas para a atividade. Por exemplo, esta tabela pode ser usada para habilidades de processo científico e suas sub-habilidades.

\section{TABELA 3 - TABELA DE CORTE TRANSVERSAL DE HABILIDADES*}

\begin{tabular}{|c|c|c|c|c|c|c|}
\hline \multirow[t]{3}{*}{ Habilidade } & \multirow[t]{3}{*}{ Sub-habilidade } & \multirow{2}{*}{\multicolumn{2}{|c|}{$\begin{array}{c}\begin{array}{c}\text { Antes da atividade } \\
\text { [Predição] }\end{array} \\
\text { Expectativa }\end{array}$}} & \multirow{2}{*}{\multicolumn{3}{|c|}{$\begin{array}{c}\text { Após a atividade } \\
\text { [Resultados da Observação do } \\
\text { Pesquisador] }\end{array}$}} \\
\hline & & & & & & \\
\hline & & Ocorre & Não ocorre & Sim & Parcialmente & Não \\
\hline \multirow{6}{*}{$\begin{array}{l}\text { Habilidades } \\
\text { de vida }\end{array}$} & Pensamento analítico & $\mathrm{X}$ & & $\mathrm{X}$ & & \\
\hline & Habilidade de decisão & $\mathrm{X}$ & & & $\mathrm{X}$ & \\
\hline & Criatividade & $\mathrm{X}$ & & $X$ & & \\
\hline & Empreendedorismo & & $\mathrm{X}$ & & & $\mathrm{X}$ \\
\hline & Comunicação & $\mathrm{X}$ & & & $\mathrm{X}$ & \\
\hline & Cooperação & $\mathrm{X}$ & & & $\mathrm{X}$ & \\
\hline
\end{tabular}

FONTE: Esta tabela faz parte do estudo realizado por Karademir (2017, our translation).

\section{Processo das etapas de atividades e avaliação}

Neste estudo realizado com estudantes com superdotação, foi oferecido um ambiente para que os estudantes pudessem pensar em projetos. Neste contexto, foi feita uma discussão para revelar os problemas que eles encontraram em suas próprias vidas. Após esta discussão, eles criaram rascunhos de desenhos de produtos originais que eles revelaram inicialmente. Um exemplo dos desenhos dos estudantes consta na Figura 4. Em seguida, se aprofundaram nos seus desenhos. Concentraram-se em adições e subtrações, e fizeram pesquisas. $\mathrm{Na}$ última etapa, terminaram seus desenhos e os transformaram em produtos. Foram feitas observações para identificar suas habilidades em todas as etapas, 
do início ao fim. Em suas apresentações sobre seus produtos, eles explicaram sua originalidade, fluência e flexibilidade.

FIGURA 5 - EXEMPLO DE UM PRODUTO CRIADO POR ESTUDANTES COM SUPERDOTAÇÃO NO ENSINO FUNDAMENTAL: ESCOVA DE DENTE COM PASTA AUTOAPLICADA

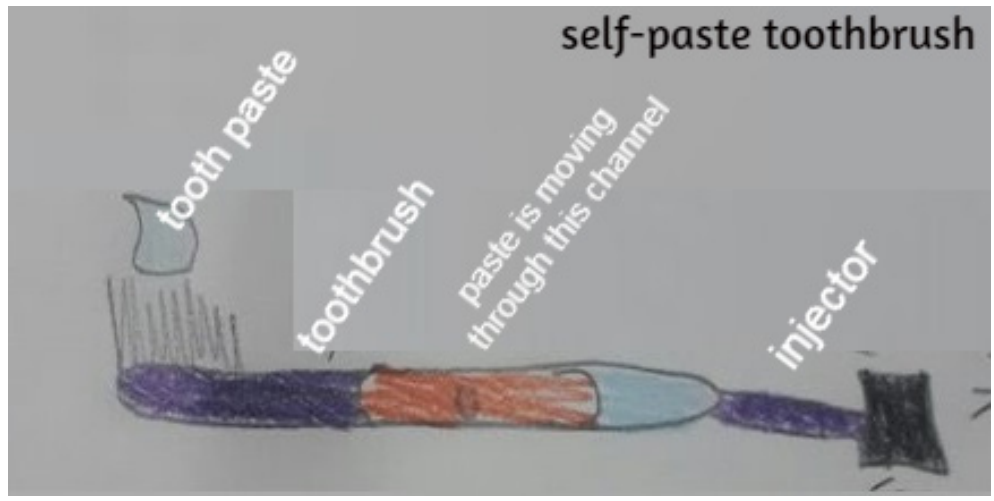

FONTE: A imagem foi tirada e editada pelo autor como parte da pesquisa.

Como visto na Tabela 4, alguns comportamentos dos estudantes e algumas características e habilidades de seus produtos correspondem. Esses comportamentos e características são especificados através de observações e avaliações feitas no processo.

TABELA 4 - DETERMINANDO AS SUB-HABILIDADES [HABILIDADES DE VIDA] ESPERADAS VISADAS

\begin{tabular}{|l|l|}
\hline Tipo de habilidade & $\begin{array}{l}\text { Característica ou comportamento exercido pelo estudante na } \\
\text { formação da habilidade }\end{array}$ \\
\hline Pensamento analítico & Retirada de materiais desnecessárias da lista de materiais \\
\hline Habilidade de decisão & Decidir quais materiais utilizar e como \\
\hline Criatividade & $\begin{array}{l}\text { Flexibilidade: Acréscimo de características diferentes ao produto que } \\
\text { vai ser revelado. } \\
\text { Originalidade: Criação de um produto original } \\
\text { Fluência: Produção de soluções para perspectivas diferentes }\end{array}$ \\
\hline Empreendedorismo & Realização de vendas que precisam ser projetadas \\
\hline Comunicação & Compartilhando opiniões com amigos no grupo \\
\hline Cooperação & Trabalho compatível / coordenado com outros colegas no grupo \\
\hline
\end{tabular}

FONTE: Karademir (2017, our translation). 


\section{Resultados da prática}

Neste estudo, observa-se que a criatividade dos estudantes mudou positivamente na criação de produtos e na utilização destes produtos na vida cotidiana. Quanto às dimensões da criatividade: na dimensão Fluência da criatividade, os estudantes mostram um desenvolvimento positivo; na dimensão Flexibilidade da criatividade, os estudantes mostram um desenvolvimento positivo; e na dimensão Originalidade da criatividade, os estudantes mostram um desenvolvimento positivo. A criatividade dos estudantes com superdotação tem aumentado com o treinamento proporcionado sobre os processos de criação de produtos.

\section{REFERÊNCIAS}

ADAMS, Robin Sue. Cognitive processes in iterative design behavior. 2001. (Ph.D. thesis) - University of Washington, Seattle, WA, 2001.

AKKANAT, Cigdem. Investigating scientific creativity levels of 7 th graders. (Unpublished Master Thesis). Gaziosmanpasa University, Educational Sciences Institute, Tokat, 2012.

ARENOFSKY, Janice. How to put creativity into your work life. Career World, v. 29, n. 1, p. 24-29, 2000.

ARGYRIS, Chris; SCHÖN, Donald. Organizational learning II: Theory, method, and practice. Reading: Addison Wesley, 1996.

BAHIA, Sara; TRINDADE, José Pedro. Transformar o velho em novo: A integração da criatividade na educação. In: PISKE, Fernanda Helen; BAHIA, Sara (org.). Criatividade na escola: o desenvolvimento de potencialidades, altas habilidades e talentos, emoção. Curitiba: Juruá Editora, 2013. p. 15-32.

BIALIK, Maya; FADEL, Charles; TRILLING, Bernie. Skills for the 21st century: what should students learn?. Boston, Massachusetts: Center for Curriculum Redesign, 2015.

BISSONNETTE, Steve; RICHARD, Mario. Comment construire des compétences en classe. Québec: Chenelière/Mac Graw-Hill, 2001.

CHUNG, Tsui-shan. Table-top role playing game and creativity. Thinking Skills and Creativity, Amsterdã, v. 8, p. 56-71, 2013. Disponível em: https://doi.org/10.1016/j. tsc.2012.06.002. Acesso em: 25 out. 2021. 
DAVASLIGIL, Umit. Gifted children due diligence commission's preliminary report book, I. Turkey Gifted Congress. Istanbul: Children's Foundation Publications, 2004.

DE CORTE, Erik. Transfer as the productive use of acquired knowledge, skills, and motivations. Current Directions in Psychological Science, [on-line], v. 12, n. 4, p. 142146, 2003. Disponível em: https://doi.org/10.1111/1467-8721.01250. Acesso em: 25 out. 2021.

GUILFORD, J. P.; HENDRICKS, Moama; HOEPFNER, Ralph. Solving social problems creatively. Journal of Criative Behavior, v. 2, n. 3, p. 155-164, 1968.

GUNES, Firdevs. Skills and competencies set forth by Bologna process in higher education. Journal of Higher Education and Science, [on-line], v. 2, n. 1, p. 1-9, 2012. Disponível em: 10.5961/jhes.2012.026. Acesso em: 25 out. 2021.

HENNESSEY, D. L. Twenty-Five Lessons in Citizenship. [S. l.]: Unkno, 2004.

HENNESSEY, Beth; AMABILE, Teresa. Creativity. Annual Review of Psychology, Palo Alto, v. 61, p. 569-598, 2010. Disponível em: https://doi.org/10.1146/annurev. psych.093008.100416. Acesso em: 25 out. 2021.

HU, Weiping; ADEY, Philip. A scientıfic creatıvity test for students. International Journal of Science Education, [S. l.], v. 24, n. 4, p. 389-403, 2002. Disponível em: http://mtt. snnu.edu.cn/_local/5/75/DE/597587DAA8D87EF4D401900A0F4_8A509B82_2F8BF. pdf?e=.pdf. Acesso em: 7 nov. 2021.

KARADEMIR, Ersin. Investigation the scientific creativity of gifted students through project-based activities. International Journal of Research in Education and Science (IJRES), Leiden, v. 2, n. 2, p. 416-427, 2016. Disponível em: https://eric. ed.gov/?id=EJ1110273. Acesso em: 25 out. 2021.

KARADEMIR, Ersin. The concept of skill in science teaching and its interdisciplinary use: Sample and application supported. Ankara: Pegem Publications, 2017.

KARADEMIR, Ersin. Skills and the place in the curriculum. At Science Curriculums. Ankara: Anagun, S. S. Ani Publication, 2020.

KOBERG, Don; BAGNALL, Jim. The Universal Traveler. Menlo Park, CA: Crisp Publications, 2003.

KOCAK, Recep; ICMENOGLU, Eda. Emotional intelligence and creativity as predictors of life satisfaction among gifted students. The Journal of Turkish Psychological Counseling and Guidance Journal, [on-line], v. 4, n. 37, p. 73-85, 2012. Disponível em: https://dergipark.org.tr/en/pub/tpdrd/issue/21457/229659. Acesso em: 25 out. 2021.

KULIK, James; KULIK, Chen-Lin. Ability grouping. In: COLANGELO, Nicholas; DAVIS, Gary A. Handbook of Gifted Education. Boston: Allyn and Bacon, 1997. v. 2, p. 230-242. 
LIN, Chongde, et al. The influence of CASE on scientific creativity. Research in Science Education, [S. l.], v. 33, n. 2, p. 143-162, 2003.

MACKINNON, Donald W. The nature and nurture of creative talent. American psychologist, v. 17, n. 7, p. 484-495, 1962.

MALAGA, Ross A. The effect of stimulus modes and associative distance in individual creativity support systems. Decision Support Systems, v. 29, n. 2, p. 125-141, 2000.

MNE. Ministry of National Education, 2016. Disponível em: http://orgm.meb.gov.tr/ meb_iys_dosyalar/2017_01/02031535_tebligler_dergisi.pdf. Acesso em: 09 nov. 2021.

OECD. Organisation for Economic Co-Operatinon and Development. The definition and selection of key competencies [Executive Summary]. Paris: OECD, 2005. Disponível em: http://www.oecd.org/dataoecd/47/61/35070367.pdf. Acesso em: 25 out. 2021.

ONUR, Dilara; ZORLU, Tulay. Theoretical Approaches towards the Concept of Creativity. Journal of the Human and Social Sciences Researches, v. 6, n. 3, p. 1535$1552,2017$.

PARTNERSHIP FOR 21ST CENTURY SKILLS (P21). Learning for the 21st century: A report and mile guide for 21 st century skills. Washington, DC: Partnership for $21 \mathrm{st}$ Century Skills, 2003.

PARTNERSHIP FOR 21ST CENTURY SKILLS (P21). 21st century skills: how can you prepare students for the new global economy? Hilliard: Partnership for 21 st century skills, 2013. Disponível em: https://www.oecd.org/site/educeri21st/40756908.pdf. Acesso em: 25 out. 2021.

PISKE, Fernanda Helen Ribeiro et al. Creativity and complex thoughts of gifted students from contributions of Edgar Morin and Rudolf Steiner. Creative Education, [on-line], v. 7, n. 15, p. 2268-2278, 2016. Disponível em: 10.4236/ce.2016.715221. Acesso em: 25 out. 2021 .

PISKE, Fernanda Helen Ribeiro et al. Creative Education for Gifted Children. Creative Education, [on-line], v. 5, p. 347-352, 2014. Disponível em: http://dx.doi.org/10.4236/ ce.2014.55044. Acesso em: 24 out. 2021.

PIXABAY. Stunning free imagee \& royalty free. Disponível em: https://pixabay.com/. Acesso em: 07 nov. 2021.

PLUCKER, Jonathan A.; BEGHETTO, Ronald; DOW, Gayle. Why isn't creativity more important to educational psychologists? Potential, pitfalls, and future directions in creativity research. Educational Psychologist, Washington, v. 39, p. 83-96, 2004. Disponível em: https://doi.org/10.1207/s15326985ep3902_1. Acesso em: 25 out. 2021.

RAHMAN, Tariq. Language, Education, and Culture. Karachi: Oxford University Press, 1999. 
RENZULLI, Joseph S. What is this thing called giftedness, and how do we develop it? A twenty-five year perspective. Journal for the Education of the Gifted, [on-line], v. 23, n. 1, p. 3-54, 1999. Disponível em: https://doi.org/10.1177/016235329902300102. Acesso em: 25 out. 2021.

SUNGUR, Nuray. Yaratıcı düşünce. [S. l.]: Evrim, 1997.

TORRANCE, E. Paul. Can we teach children to think creatively?. Journal of Creative Behavior, Washington, v. 6, n. 2, p. 114-143, 1972. Disponível em: https://doi. org/10.1002/j.2162-6057.1972.tb00923.x. Acesso em: 25 out. 2021.

TORTOP, Hasan Said. Differentiated teaching curriculum differentiation in gifted education models. Düzce: Young Bilge Publishing, 2015.

USTUNDAG, Tulay. Journey to creativity. Ankara: Pegem Publications, 2002.

WECHSLER, David. Manual for the Wechsler intelligence scale for children-third edition. San Antonio, TX: The Psychological Corporation, 1991.

WEISS, Howard. Creative problem solving. New York: American Management Association, 1993.

Texto recebido em 17/06/2021.

Texto aprovado em 23/08/2021. 